\title{
An annotated history of the principles of cultivated plant classification
}

\author{
W. L. A. HETTERSCHEID*, R. G. VAN DEN BERG $\dagger$ and \\ W. A. BRANDENBURG \\ *Vaste Keurings Commissie, Linnaeuslaan 2a, 1431 JV Aalsmeer, The Netherlands; \\ $\uparrow$ Department of Plant Taxonomy, Wageningen Agricultural University, PO Box 8010, \\ 6700 ED Wageningen, The Netherlands and $\ddagger$ Centre for Plant Breeding and Reproduction \\ Research, PO Box 16, 6700 AA Wageningen, The Netherlands
}

\section{CONTENTS}

Introduction 123

Pre-Linnean times $\quad 124$

Linnaeus $\quad 124$

The nineteenth century $\quad 125$

The twentieth century 125

The International Code of Nomenclature for Cultivated Plants (ICNCP) 128

Recent developments 128

Conclusion $\quad 132$

Summary 133

Acknowledgements 133

References 133

Key-words: classification, cultivated plants, culton, nomenclature, systematics, taxon, taxonomy.

\section{INTRODUCTION}

Man has learned to manipulate his surroundings in a profound way. It is evident that all creatures on earth interact with their surroundings resulting in minor or major changes. Man's way of manipulating seems to differ, however, in one important respect and that is his strong will to manipulate in planned directions. This is in clear contrast to instinctive manipulation as seen in other animals. In order to improve his surroundings and his food Man started to select plants from the wild that were suitable to his purposes. Those plants not yet ideally suited he learned to modify in diverse ways, leading to the origin of cultivated plants. The resulting wealth of variation soon led to the need to classify these new forms. Because there is an obvious relation between cultivated plants and those growing in the wild, classification and nomenclature of both types of plants have always been strongly connected. Linnaeus finally standardized the nomenclature for plants and decided to classify cultivated plants subordinate to wild plants but to otherwise use the same type of nomenclature. This step has pervaded the systematics, taxonomy and nomenclature of cultivated plants until today. Many attempts have been made to keep systematic categories of cultivated plants under the

(C) 1996 Royal Botanical Society of The Netherlands 
influence of classificatory philosophies relating to wild plants and they have all been unsatisfactory.

Many special categories for cultivated plants have been proposed but only few have survived, notably the cultivar and the (cultivar-)group. Recently, however, a systematic theory has been proposed that emphasizes the distinctions between the goals of classifying wild plants and cultivated plants. It is emphasized that this distinction is much clearer than has always been recognized and a new general term for systematic categories of cultivated plants the culton, has been proposed. The historical/ philosophical survey below illustrates the development of systematic thought in cultivated plant taxonomy leading to the proposal of the culton concept.

\section{PRE-LINNEAN TIMES}

Written history about man cultivating plants and distinguishing between different kinds goes back to Roman times (Stearn 1986). Names for certain types of cultivated plants (cultivars) were often derived from common names and Latinized but also nontranslated names in common language were used. In most crops distinctions between named cultivars was easy because of the relatively low numbers but, for instance in tulips, the situation was different. Tulip cultivars were bred in great numbers and in an overwhelming variety, and the need to create a classification above the cultivar level developed. Clusius (1601) presented the first classification of cultivated tulips, based on flowering time and flower stalk length (see also Van Raamsdonk \& De Vries 1996). These characters, important to growers and the public, were given decisive weight in the classification and were apparently deemed more important by Clusius than other obvious morphological characters (colour, tepal morphology). Consequently, by the time Linnaeus published his magnum opus (1753) the systematics of cultivated plants had reached the point where it was understood that the entities to be classified were different from those occurring in the wild.

\section{LINNAEUS}

Linnaeus was well aware of the fact that Man produced plants that need to be differentiated nomenclaturally from plants occurring in the wild which, in his opinion, were God's creations. He therefore classified the cultivated element of a species in subspecific categories, which were later called varieties. Therefore Linnaeus became the first to explicitly create a separate systematic category for cultivated plants. Because he was opposed to discussing cultivated plants and wild occurring plants (his 'species') together in the botanical society (Wijnands 1986) and he preferred to disallow interest in cultivated plants to florists or 'beginners in botany', he deemed it useful to make these cultivated plants known through the aforementioned categorical separation. In one of his firm statements he suggested that the system of cultivated plants should be excluded from the nomenclatural system entirely. Had he been able to do this, we would probably have been spared many of the systematic and nomenclatural problems in cultivated plant taxonomy that we experience today. However, Linnaeus did not do so and later botanists have integrated the varietal system into the systematics of plants occurring in the wild and at the same time, dragged all the cultivated plants for which Linnaeus created the varieties into the realm of classification systems for wild plants, resulting in much confusion and long-standing debates over the way in which systematic categories

(C) 1996 Royal Botanical Society of The Netherlands, Acta Bot. Neerl. 45, 123-134 
of cultivated plants could be fitted properly into the taxonomic (Linnean) categorical hierarchy. Another consequence is that, in many cases, the names of these Linnean varieties became dogmatic and were never adapted to a modern nomenclature for cultivated plants. They continued to be treated as proper taxa and often became the reason for much instability in cultivated plant nomenclature.

\section{THE NINETEENTH CENTURY}

Until the twentieth century no one seemed to have questioned Linnaeus's treatment of cultivated plants and as a result the common nomenclature for wild and cultivated plants remained unchallenged. Darwin $(1859,1868)$ took the variants of animals and plants produced under domestication as the starting point of his theory of evolution but he drew no conclusions as to the need for a different classification of the organisms originating under domestication or as a result of evolution alone.

During the latter part of the nineteenth century Alefeld (1866), in his 'Landwirtschaftliche Flora', promoted infraspecific classification of cultivated plants in so-called 'Varietaeten-Gruppen', a precursor of the convariety, the latter finally being taken up in the 1952 edition of the International Code of Nomenclature for Cultivated Plants (hereafter referred to as ICNCP) and given Latin names with formal descriptions. Alefeld was also the first to designate cultivars consistently with Latin epithets and formal descriptions. In certain crops (e.g. Pisum, Hordeum), Alefeld's convarieties remained in use for a long time (Parker 1978).

In 1867 A. P. De Candolle presented his 'Lois de la Nomenclature Botanique' which were discussed at botanical congresses in Paris (1900), Vienna (1905) and Brussels (1910), leading to the publication of subsequent editions of the Règles de la Nomenclature Botanique. Cultivated plants are only mentioned occasionally in these documents. In the 1905 edition it says:

Recommendation I: '(. . .) Modifications of cultivated plants should be associated, as far as possible, with the species from which they are derived.'

Article 11: 'In many species we distinguish varieties (varietas) and forms (forma) and in some cultivated species, modifications still more numerous; (...).'

Article 30: 'Forms and half-breeds among cultivated plants should receive fancy names, in common language, as different as possible from the Latin names of species and varieties. When they can be traced back to a species, a subspecies or a botanical variety this is indicated by a succession of names.'

From these citations it is evident that the classification of cultivated plants was considered an integral part of the classification of wild plants, but that the distinction was to be made manifest in a clearly different nomenclature. Unfortunately no one saw the struggle this was going to bring by the use of only one set of nomenclatural rules, which in themselves support only one basic type of classifications (the hierarchical, Linnean way).

\section{THE TWENTIETH CENTURY}

Bailey (1918) published a paper in which he argued for separate recognition of entities of cultivated plants. He feared that a common nomenclature for these entities and (C) 1996 Royal Botanical Society of The Netherlands, Acta Bot. Neerl. 45, 123-134 
categories of wild plants (his 'indigens') would fail to illustrate their ontological difference. Based on the lack of knowledge of the origin of species that were known only in cultivation, he proposed the term 'cultigen' for these. With this definition the cultigen became an equivalent of the species category, although Bailey did not propose how the nomenclature of the cultigens should differ from that of the indigens. Bailey (1923) defined the principal fundamental subdivision of the cultigen and named it 'cultivar', the variant produced by Man's handling of members of a species. With these two publications, Bailey became the first to propose a more fundamental systematic separation of classifying and naming wild and cultivated plants. During the years, however, the term cultigen has lost its original meaning and is now used with several redefinitions. It is used mainly as a general term for gene pools originated in cultivation and of whatever systematic category, but more confusion exists. Jirásek (1958) mentioned the cultigen as the oldest designation of the cultivar but deviates here from Bailey's original definition.

Approximately three decades after Bailey a number of east European and Russian taxonomists (e.g. Mansfeld (1953, 1954), Pangalo (1948), Grebenscikov (1949) and Jirásek $(1958,1961))$ apparently felt the need to put greater emphasis on the complicated and numerous kinds of relations between cultivars and their wild relatives and among cultivars. Also a need was felt to separate several different types of cultivars and use different categories for them. There was a general feeling that all these categories must fit the taxonomic hierarchy at subspecific levels. Within 10 years, no less than $c .50$ such categories were proposed (Jirásek 1961). Some of these will be discussed here in relation to an influential paper written by Mansfeld.

Mansfeld $(1953,1954)$ presented a lengthy essay in two parts on the systematics of cultivated plants. He argued for a hierarchical system in which all elements at one particular level are exhaustively classified. No element is to be left out of the classification. This is a major characteristic of the Linnean hierarchy in use for taxa. Mansfeld opted for a closed classification (for a discussion of 'open' versus 'closed' classifications see Brandenburg et al. 1982; Brandenburg 1986a; Hetterscheid \& Brandenburg 1995). He continued with an exposé of the varied ways in which cultivated plants are manipulated and altered by Man relative to their wild progenitors. As a consequence he claimed that more than one classification system is necessary for cultivated plants but all must start from the cultivar as the fundamental category. He then proposed three general classification principles for cultivars:

(1) based on the position of their wild progenitors in the taxonomic hierarchy;

(2) based on their use; and

(3) based on the ways they are maintained in cultivation.

Mansfeld also acknowledged that classifications as above are artificial. Therefore he proposed a number of categories to be used, most of which have their parallel in the taxonomic hierarchy, but since the latter categories were used for wild plants he argued that they are unsuitable for cultivated plants. This is essentially what Bailey had said in 1918 and 1923. Mansfeld's categories are specioid, subspecioid, convar, provar, nidus and cultivar. Of these, the convariety dates back to Grebenscikov (1949) and the nidus to Pangalo (1948). The other terms (except cultivar) were newly proposed. All categories had to comply with the rules of nomenclature as set out in ICBN. Needless to say, a classification based on such a multilevel categorical system presents a remarkable inflation of the number of Latin epithets (e.g. Helm 1957). 
It is clear from this that Mansfeld also felt the urge to stay in line with the Linnean hierarchy and the technical and nomenclatural mechanisms as defined in the ICBN. The ICBN, on the other hand, gave (and still gives) ample opportunity to create multilevel hierarchies of additional categories not mentioned within it. In this way highly complicated taxonomies were invented to accommodate the complex variation patterns of cultivated plants into a Linnean hierarchy with, for instance, the following result (Helm 1957):

Beta vulgaris subsp. vulgaris convar. vulgaris provar. flavescens f. leucopleura.

Every successive classification of such a crop had to deal with all these names, and while staying within the same (Linnean) classification system, could present an equally complicated alternative. The characters used to differentiate the 'taxa' in different levels or the 'taxa' at one level often no longer had any connection with the usage of the cultivars and so a taxonomic literature developed which was largely impenetrable for human society with the exception of the taxonomists themselves. A second by-product was the tremendous instability of these systems, which was a menace to the everyday users of the crop. This instability was brought about by the idiosyncrasies of taxonomists who were out of touch with society, and the technical nomenclatural intricacies of ICBN. Naturally, society ignored these taxonomies and reverted to the use of common names even when these were not well anchored to an existing taxonomy.

Although Mansfeld came as close as Bailey to devising a separate system of categories for cultivated plants, he failed to divorce his ideas from the classification philosophy in use for wild plants. He and several authors with him (e.g. Lehmann 1955; Hammer 1981; Ivanjukovich 1981; Kühn 1981; MacKey 1981; Perrino et al. 1986) until today have treated systematic categories of cultivated plants as taxa. Because of this they always had to turn their attention to ICBN for the naming of these 'cultivated taxa' and used the underlying mechanism of closed classifications. In their urge to use the Linnean nomenclature, they failed to see the value of the common names that already existed for most of their cultivated taxa. In Helm's (1957) treatment for every such 'taxon' one or a few common names are given, but these are not used in the taxonomy.

Jirásek (1958) came one step closer to a fundamental separation of the taxonomy of wild and cultivated plants when he proposed a general term for all systematic categories of cultivated plants, the 'taxoid' (later 'taxonoid'). He defined it as: 'a collective designation for individual taxonomic categories for the systematic classification of cultivated plants'. His philosophy for the taxoid is based on the obvious ontological difference between wild plants and cultivated plants. He also distinguished between multicharacter ('natural') classifications and few-character ('artificial') classifications and acknowledged that the latter should be used for cultivated plants. He even stressed that the need for artificial classifications of cultivated plants is in line with the needs of the users and claimed that a taxonomist should choose a classification character that has the most benefit for the user. Alas, he did not draw this line of thought to its final conclusion, which would have been the separation of the naming of his taxoids from the ICBN mechanisms as was later proposed by Hetterscheid \& Brandenburg (1995). Instead he proposed a system of subordinate 'taxoides' and in the process invented five new ones, all subdivisions of existing categories. The most puzzling category he proposed was the subcultivar, with which he suddenly broke with tradition that the cultivar was the basal (and therefore indivisible) category of the system. In Linnean terms this proposition is understandable since no restriction exists in ICBN for the (C) 1996 Royal Botanical Society of The Netherlands, Acta Bot. Neerl. 45, 123-134 
proposition and use of additional categories. In terms of artificial systems, this mechanism is by no means obligatory.

\section{THE INTERNATIONAL CODE OF NOMENCLATURE FOR CULTIVATED PLANTS (ICNCP)}

In the midst of this taxonomic turmoil a proposal for an independent ICNCP was published (Appendix III to the Stockholm Code 1952). In section $\mathrm{H}$ of this proposal, special categories for the classification of cultivated plants were defined: line, clone, hybrid-group (grex), line-hybrid and convariety. The latter's definition (Grebenscikov 1949) was simplified to 'a group of closely allied cultivars, somewhat analogous to the subspecies'. This could be taken to reflect a dawning realization of the fundamental differences between the classification of wild and cultivated plants, but subsequent editions of the ICNCP (from 1953 onwards) do not show this. In the first independent edition of the ICNCP (Stearn 1953) Grebenscikov's convariety was taken up with the aforementioned simplified definition and used for cultivars grouped on the basis of similarity of characters 'important to cultivators'. However, the way in which the nomenclature of the convariety was treated illustrates the ICNCP's ambiguous relation with the ICBN: convarieties with Latin names ought to be published with Latin descriptions. In the 1958 edition of ICNCP (art. 14) the convariety was classified as a supplemental category and from then on had to comply with ICBN rules. Also its definition was no longer given in the text. Finally, in the 1969 edition the convariety was no longer mentioned. The convariety in its original ICNCP (1953) definition had been supplanted by the 'group'.

A very prominent feature of the 1953 edition of ICNCP is the extensive attention given to cultivated plants resulting from hybridization. Most of this attention was focused on how to give such hybrids names according to the ICBN. For this the ICBN Hybrid Appendix was adapted and now seems to be almost entirely devoted to cultivated plants (see for instance the examples). Again, the logic of a more fundamental separation of nomenclature of cultivated and wild plants was not recognized despite all foregoing literature that seemed to call for this. A special category for certain hybrid products in orchids was introduced in the 1953 edition of the ICNCP as the grex which designates a group of plants (not necessarily named cultivars) that arose from a given cross. This category has figured prominently in later ICNCP editions but has not gained much acceptance outside orchid nomenclature. The code Commission therefore decided to take grex from the main body of rules of ICNCP (Trehane et al. 1995) and defer it to a note that refers to the Handbook in Orchid Nomenclature and Registration.

Since the ambiguous approach of ICNCP towards ICBN did not change essentially in all later editions until 1995 (Trehane et al. 1995), a body of literature has accumulated with quite different and incoherent approaches to the classification and nomenclature of cultivated plants, some of which will be commented upon in the next sections.

\section{RECENT DEVELOPMENTS}

Jeffrey (1968) recognized that formal botanical subspecific classification is unsuited to accommodate cultivated plants. He proposed a categorical system between two 'fixed' points of reference for the classification of cultivated plants, these points being the cultivar (the lower 'limit') and the species (the 'upper' limit). The choice of the species 
was unfortunate since this limit is by no means fixed for cultivated plants and is therefore not an obligatory part of a cultivar's name. Jeffrey opted for a multidiscipline analysis (for instance cytology, genetics, genecology, morphology, etc.) of cultivated plants which should unequivocally reveal the relationship of cultivated plants to their wild relatives. This particular relationship was to be the basis for a classification. $\mathrm{He}$ then proposed to use two main categories in a hierarchical setting between cultivar and species, namely provar. and convar. He stated that their names should not follow the ICBN and thus should not be in Lation form. His examples, however, again fail to address the resulting problem of long and cumbersome names. The many characters used to propose such a system to the full render it very vulnerable to changes (instability). It also is rather academic in its use of characters and does not seem to appreciate the needs of less scholarly users. To distinguish wild and cultivated forms of one species he proposed to use additionally the 'subspecioid' for the cultivated aspect of a species, thereby trying to link the two different classification systems of wild and cultivated plants.

Harlan \& De Wet (1971) promoted a 'rational' classification of cultivated plants using a genetic/biosystematic perspective. Their basis is the biological species, and the concept of crossability is decisive in their division of the total gene pool of cultivated plants into a primary, secondary and tertiary gene pool, depending on the degree of crossability between individual cultivated plants. Although they agree with Jeffrey (1968) that formal botanical categories at the infraspecific level do not satisfy for classifying cultivated plants, they propose to establish entire subspecies to accommodate 'cultivated races' of a species. This approach has the same flaws as the biological species. Proposing classifications entirely on the concept of crossability is not operational. It also presumes that genetic coherence/identity is a proper argument for classifications in general, whereas this is only one aspect of classification and it ignores other classificatory needs of users of cultivated plants. Then there are the large numbers of cultivars that have been produced by crossing several species. They can never be classified as part of one particular species. Further, Harlan \& De Wet argue that crossability barriers between gene pools of cultivated plants may also be the basis for proposing separate (biological) species. Here the confusion between the evolutionary context and that of cultivated plants is obvious. Because an overwhelming majority of present-day cultivars cannot be traced directly to one particular species, Harlan \& De Wet's rationale would only be applicable (if at all) to a minority of cases.

Shortly before the first edition of ICNCP, at the Stockholm Botanical Congress (1950), the word 'taxon' was adopted to supplant the term 'taxonomic group' as used in ICBN. This catch-all term for systematic categories of plants was intimately associated with ICBN because the nomenclature of taxa had to be ruled by ICBN and, conversely, all systematic groups of which the nomenclature was according to ICBN were taxa by definition. How then was it possible that taxonomists of cultivated plants did not raise questions as to the categories they were using and that were not part of ICBN? This refers especially to the cultivar and the cultivar-group. To this day, some also believe that systematic groups of cultivated plants are taxa but here an anomaly arises between their explanation of taxa and that of ICBN. To complicate matters, ICBN does recognize hybrids of cultivated origin within its limits and so does ICNCP, with the result that a cultivar derived from artificial hybridization may be given an extra-long name or even two totally different kinds of names because it may be given a name using 
both codes. The lack of a consistent philosophy of what constitute systematic categories of cultivated plants is extremely obvious from this. Apparently some of these categories are typically not taxa, because they do not figure in ICBN, but others may be both! The most explicit statement showing this confusion is in the 1980 edition of ICNCP (art. 10 note 2 , art 26) which leads one to conclude that cultivar (cultivar-)group and species are part of one system, whereas they clearly are not.

This confusion has pervaded taxonomic literature up to the present day. The (often unconscious) assumption that systematic groups of cultivated plants are taxa has resulted in many attempts at transposing methods in use for classifying taxa into the realm of the taxonomy of cultivated plants. Terms such as 'phylogenetic relationships', 'biological species concept' (Harlan \& de Wet 1971, see above) and 'multicharacter classification' used in the context of cultivated plant systematics are good examples. Baum (1981), for instance, advocates classifications based on multicharacter analysis as in use for taxa. An obvious result is overlapping character distributions among groups. It is apparently not taken into consideration that, more often than not, users of cultivated plants require classifications based on only a few characters, important to the application, cultivation or breeding direction. Such classifications do not lead to overlap of the relevant characters between the cultivargroups because the limits of these groups are fixed using those (few) characters. Often these characters have been the subject of improvement through new breeding strategies in a particular crop. It is not made clear in Baum's (1981) text why a multicharacter analysis is necessary. The objective of reconstructing pedigrees cannot serve as an argument because methods of numerical analysis are not devised for this, as became clear when phenetic methodology was first introduced in taxonomy. However, the urge to make phylogenetic statements has often corrupted the outcome of many phenetic studies. Similarly, cultivar pedigree cannot be traced back through numerical analysis. The only outcome is a statement on similarity between 'entities' (cultivars according to Baum) but this similarity need not reflect pedigree. It is particularly cladistic methodology that has made the evaluation of similarity in terms of pedigree/phylogeny operational. Having said that, Baum's (1981) paper is remarkable because it contains a very early denouncement of hierarchical thinking in the taxonomy of cultivated plants. On the other hand, to speak of 'infraspecific' variability (see Baum's title) is illogical in this context. It is a hierarchical statement suggesting that the variability of cultivated plants is part of a hierarchy, i.e. the taxonomic one. Another example of the confusion of systematic categories of cultivated plants with taxa.

The phenomenon of hierarchical character patterns in cultivated plants has been addressed by Pickersgill (1986) in an attempt to underscore the usefulness of the category 'subspecioid' in the taxonomy of cultivated plants. The histories of introduction into cultivation of the crop examples she uses (Capsicum, Arachis, Vicia) are analysed and a reconstruction of their domestication is presented.The scenarios, however, contain speculations as to the order and extent to which certain processes have contributed to today's character pattern in cultivars of the crops mentioned, as well as uncertainties as to what may happen in the near future. The supposed hierarchy displayed by the distribution of characters is therefore ephemeral and also at least partly based on random selection activities of Man. The danger of secondary domestication based on totally different characters of the wild relatives of the crops, will blur the hierarchy. The repeated occurrence of domestication processes in one and the same 
crop is one of the major factors undermining the rationale of focusing attention to hierarchy in the taxonomy of cultivated plants, let alone expressing it in a hierarchical classification of 'taxa'. It also explains why a multicharacter approach to propose a single (hierarchic) classification of such a crop fails. The different starting points of the multiple domestications are random and do not have any relation to each other. Although it is not inconceivable that a hierarchical classification of cultivars of (part of) a crop may be useful, it must be borne in mind that inflation of ranks will soon be the result of that approach, as has been proven in history several times (see above). Furthermore, such special purpose classifications are usually based on a very limited number of characters, for which hierarchic classification is unnecessary. We therefore advocate focusing attention on non-hierarchical classifications of cultivars. It is often simple to deflate a hierarchical classification in the Linnean sense to a one-level classification using cultivar-groups.

Phenetic methods have been introduced to describe and analyse crop/weed complexes, or as often stated 'the relation between cultivated plants and their wild relatives'. Such analyses are often presented as being an aid in breeding programmes. A debatable part of many of these analyses (e.g. Hawkes 1981; Whalen 1991) is the treatment of all terminal entities (OTUs) as taxa, often species, while it is perfectly well known to the author(s) that some of the OTUs are entirely cultigenic (see also below). The question arises as to what kind of relationship can be analysed between two ontologically different OTUs? Certainly not any phylogenetic one, which is often suggested as being helpful for breeders. Numerical methods and the unequal ontology of the OTUs simply do not allow for such conclusions.

The unsubstantiated view that systematic categories of cultivated plants are not essentially different from taxa denies all past efforts to divorce the nomenclature of wild and cultivated plants, even though all these attempts have not been brought to a final conclusion. It also denies the fact that ICBN does not recognize the two most essential categories of cultivated plants in its system, the cultivar and the cultivargroup. The remaining bonds between ICBN and ICNCP (notably the nomenclature of hybrids of cultivated origin) have been criticized by Brandenburg \& Schneider (1988) as being the cause of an incoherent nomenclature for cultivated plants. Also the past creation of extensive subspecific hierarchies of 'taxa' to accommodate cultivated plants (see above) is ample proof of the wrong ways that have been chosen to classify cultivated plants, on the basis of this misconception. In several papers (Brandenburg 1986a,b 1991; Brandenburg et al. 1982) a greater emphasis is given to the use and formation of cultivar-groups, as well as to 'open' versus 'closed' classifications, the former useful for cultivated plants and the latter obligatory for wild plants. In these papers people are urged not to use the complicated system of naming hybrids under the rules of the ICBN. Illustrations of a consistent use of cultivar-groups as useful taxonomic categories for cultivated plants instead of the use of nothotaxa (below the nothogenus) may be found in, for instance, Brandenburg (1989), Hoffman (1996), Lester (1986) and in many volumes of the PROSEA handbook (e.g. Siemonsma \& Piluek 1993).

Hetterscheid \& Brandenburg (1995) published a more fundamental paper on the systematics of cultivated plants in an attempt to put into words and terms that which seems to have been recognized for some time, namely the fact that systematic categories of cultivated plants have a 'nature' of their own and are quite different from taxa. This different nature is brought about by several aspects. Basically domestication is an array

(C) 1996 Royal Botanical Society of The Netherlands, Acta Bot. Neerl. 45, 123-134 
of processes, largely guided by Man but at least made possible through the interference of Man. These processes when viewed separately often have their equivalent in the evolutionary landscape. However, they are imposed on plants by Man in different ways and according to Man's intention. The resulting diversity therefore is not comparable to diversity in nature. We therefore feel that it is an anomaly to speak of 'speciation under domestication' (e.g. De Wet \& Harlan 1975; Pickersgill 1977, 1986; Zohary 1984; Raamsdonk 1993; Smartt \& Simmonds 1995). The patterns of character distribution of cultivated plants therefore should not be subjected to methods of analysis or classification that are in use for describing nature's diversity. The methodological/ philosophical fundament of the systematics of wild plants is essentially different and is based on evolutionary thinking. Consequently systematic categories used to classify and give names to wild plants cannot, as a rule, be used for cultivated plants. It seems obvious that the use of similar categories for essentially different subjects can only lead to confusion and unprofitable classifications (see above). Hetterscheid \& Brandenburg (1995) therefore argue for a more fundamental separation between the systematics of cultivated and wild plants. The term 'culton' is explained to cover in general systematic groups of cultivated plants, as opposed to 'taxon' in use for systematic groups of wild plants. The culton concept underscores the awareness that both types of systematic thinking start at the base with an immediate separation of the entities they work with. This basal separation may, for instance, serve to unravel many questions regarding crop-weed complexes. In many analyses of such complexes, the basal entities have not been sorted out and separated. The mere fact that in crop-weed complexes species binomials are used is often the basis for the misconception that these names stand for actual natural species. More often than not, such 'species' are not natural but assemblages of cultigenic individuals, who have unfortunately been classified using the taxon 'species', whereas in fact they are a group of culta. Such aggregates do not react as one entity, as is envisaged for species and therefore should not be addressed as such in an analysis (Whalen 1991).

Taxonomic debate over Latin (hybrid) binomials for entities that are not taxa but culta (Radcliffe-Smith 1986; Yeo 1986; Heath 1988) may also be avoided because the problems addressed in such discussions are usually phantom problems, brought about by a wrong application of ICBN nomenclature for culta. Here, the same awareness that the basal entities are either culta or taxa will guide the nomenclature to the proper codes to be used. Hetterscheid \& Van den Berg (1996) illustrate a way in which nomenclatural debate over ICBN names can be avoided in 'cultonomy' when such names prove to represent culta instead of taxa.

\section{CONCLUSION}

The history of systematic thought concerning cultivated plants is wrought with a long-standing struggle to qualify the relationship between cultivated plants and wild plants. This relation appears not to be reducible to one comprehensive description. The (at least partly) random ways in which Man has altered the characters of plants taken from the wild can be tagged with the collective term 'domestication' but there it ends. The variation patterns in cultivars resulting from domestication therefore cannot be classified on the basis of one prevailing theory about their origin. We agree with Baum (1981) that such patterns do not call for hierarchic ordering but we disagree with him that the concept of phylogeny is applicable to cultivars. Our conclusion is that

(C) 1996 Royal Botanical Society of The Netherlands, Acta Bot. Neerl. 45, 123-134 
systematic categories of cultivated plants do not comply with the taxon concept. The new ICNCP (Trehane et al. 1995) is an attempt to give status to the special needs in classifying cultivated plants. The recent paper by Hetterscheid \& Brandenburg (1995) provides a justification for the implementation of a more fundamental separation of the systematics of cultivated plants from that for wild plants by the introduction of the culton concept.

\section{SUMMARY}

Important episodes in the history of the classification of cultivated plants are highlighted and commented upon in the light of recent developments in the systematics of cultivated plants. It is shown that throughout history, a division between classifying cultivated plants and plants as found in nature has existed in the minds of most taxonomists, but the slow development of systematic thought in cultivated plant taxonomy has slowed down progress in this field and left ample opportunity for too strong an influence of the taxon concept. As a result, the nomenclature of cultivated plants has always leaned heavily on the International Code of Botanical Nomenclature,

\section{ACKNOWLEDGEMENTS}

We would like to thank Prof. Dr ir L.J.G. van der Maesen (Netherlands), Dr L.W.D. van Raamsdonk (The Netherlands) and Mr R.P. Trehane (UK) for fruitful discussions.

\section{REFERENCES}

Alefeld, F. (1866): Landwirtschaftliche Flora. Wiegandt \& Herpel, Berlin.

Bailey, L.H. (1918): The indigen and cultigen. Science 47: 306-309.

Bailey, L.H. (1923): Various cultigens, and transfers in nomenclature. Gentes Herb. 1: 113-115.

Baum, B.R. (1981): Taxonomy of the infraspecific variability of cultivated plants. Kulturpflanze 29: 209-239.

Brandenburg, W.A. (1986a): The objectives in classification of cultivated plants. In: Styles, B.T. (ed.), Infraspecific Classification of Wild and Cultivated Plants, pp.87-98. Clarendon Press, Oxford.

Brandenburg, W.A. (1986b): Classification of cultivated plants. Acta Hortic. 182: 109-115.

Brandenburg, W.A. (1989): Clematis. In: Walters, S.M. et al. (eds), The European Garden Flora, Vol. 3: pp. 357-364. Cambridge University Press, Cambridge.

Brandenburg, W.A. (1991): The need for stabilized plant names in agriculture and horticulture. In: Hawksworth, D.L. (ed.), Improving the Stability of Names: Needs and Options, pp. 23-31, Regnum Veg. 123. Koeltz, Königstein, Germany.
Brandenburg, W.A., Oost, E.H. \& Van den Vooren, J.G. (1982): Taxonomic aspect of the germplasm conservation of cross-pollinated plants. In: Porceddu, E. \& Jenkins, G. (eds), Seed Regeneration of Cross-pollinated Plants, pp. 33-41. Balkema, Rotterdam.

Brandenburg, W.A. \& Schneider, F. (1988): Cultivar grouping in relation to the Intenational Code of Nomenclature for Cultivated Plants. Taxon 37: 141-147.

Clusius, C. (1601): Rariorum plantarum historia ... Plantin, Antwerpiae.

Darwin, C. (1859): On the Origin of Species. John Murray, London.

Darwin, C. (1868): The Variation of Animals and Plants Under Domestication. John Murray, London.

De Candolle, A.P. (1867): Lois de la Nomenclature Botanique. Paris.

De Wet, J.M.J. \& Harlan, J.R. (1975): Weeds and domesticates: evolution in the man-made habitat. Econ. Bot. 29: 99-107.

Grebenscikov, I. (1949): Zur morphologischesystematischen Einteilung von Zea mais L. unter besonderer Berücksichtigung der südbalkanischen Formen. Züchter 19: 302-311.

(C) 1996 Royal Botanical Society of The Netherlands, Acta Bot. Neerl. 45, 123-134 
Hammer, K. (1981): Problems of Papaver somniferum classification and some remarks on recently collected European poppy land-races. Kulturpflanze 29: 287-296.

Harlan, J.R. \& De Wet, J.M.J. (1971): Toward a rational classification of cultivated plants. Taxon 20: $509-517$.

Hawkes, A.D. (1981): Biosystematic studies of cultivated plants as an aid to breeding research and plant breeding. Kulturpflanze 29: 327-335.

Heath, P.V. (1988): What is a nothocultivar? Taxon 37: 960.

Helm, J. (1957): Versuch einer morphologishsystematischen Gliederung der Art Beta vulgaris L. Züchter 27: 203-222.

Hetterscheid, W.L.A. \& Brandenburg, W.A. (1995): Culton versus taxon: conceptual issues in cultivated plant systematics. Taxon 44: 161175.

Hetterscheid, W.L.A. \& Van den Berg, R.G. (1996): Cultonomy of Aster L. Acta Bot. Neerl. 45.

Hoffman, M, (1996): Cultivar classification of Philadelphus L. (Hydrangeaceae). Acta Bot. Neerl. 45.

Ivanjukovich, L.K. (1981): Specific and intraspecific classification of Sorghum species of the ser. Bicoloria (Snowd.) Ivanj. et Doron. and of the ser. Caffra (Snowd.) Ivanj. et Doron. Kulturpflanze 29: 273286.

Jeffrey, C. (1968): Systematic categories for cultivated plants. Taxon 17: 109-114.

Jirásek, V. (1958): Taxonomische Kategorien der Kulturpflanzen. Index. sem. Hort. Bot. Univ. Carol. Praha: 9-16.

Jirásek, V. (1961): Evolution of the proposals of taxonomical categories for the classification of cultivated plants. Taxon 10: 34-45.

Kühn, F. (1981): Problems of the infraspecific taxonomy of wheat. Kulturpflanze 29: 267-272.

Lehmann, C.O. (1955): A morphological system for cultivated tomatoes (Lycopersicon esculentum Mill.). Zïchter 3: 1-64.

Lester, R.N. (1986): Taxonomy of scarlet eggplants, Solanum aethiopicum L. Acta Hort. 182: 125-132.

Mackey, J. (1981): Comments on the basic principles of crop taxonomy, Kulturpflanze 29: 199-207.

Mansfeld, R. (1953): Zur allgemeinen Systematik der Kulturpflanzen I. Kulturpflanze 1: 138-155.

Mansfeld, R. (1954): Zur allgemeinen Systematik der Kulturpflanzen II. Kulturpflanze 2: 130-142.

Pangolo, K.L. (1948): Novyje principy vnutrividovoj sistematiki kulturnych rastenij [New principles for the infraspecific systematics of cultivated plants]. Bot. Zurn. 33: 151-155 [in Russian].
Parker, P.F. (1978): The classification of crop plants. In Street, H.E. (ed.), Essays on Plant Taxonomy, Academic Press, London.

Perrino, P., Hammer, K. \& Hanelt, P. (1986): Carosello and the taxonomy of Cucumis melo L., especially of its vegetable races. Acta Hort. 182: 95-100.

Pickersgill, B. (1977): Taxonomy and the origin and evolution of cultivated plants in the New World. Nature 268: 591-595.

Pickersgill, B. (1986): Evolution of hierarchical variation patterns under domestication and their taxonomic treatment. In: Styles, B.T. (ed.), Infraspecific Classification of Wild and Cultivated Plants, pp. 191-209. Clarendon Press, Oxford.

Radcliffe-Smith, A. (1986): Apologia mea propter nomina spuria non rite facta secundum notulas quae in legibus sydneiis (anno 1983) inveniendae sunt. Taxon 35: 349.

Siemonsma, J.S. \& Piluek, K. (eds) (1993): Vegetables. PROSEA 8. Pudoc Scientific Publishers, Wageningen.

Smartt, J. \& Simmonds, N.W. (eds) (1995): Evolution of crop plants, 2nd edn. Longman, London.

Stearn, W.T. (ed.) (1953): International Code of Nomenclature for Cultivated Plants. IAPT, Utrecht, London.

Stearn, W.T. (1986): Historical survey of the naming of cultivated plants. In: Maesen, L.J.G. Van Der (ed.), First International Symposium on Taxonomy of Cultivated Plants. Acta Hort. 182: 19-28.

Trehane, R.P. (ed.), Brickell, C.D., Baum, B.R., Hetterscheid, W.L.A., Leslie, A.C., McNeill, J., Spongberg, S.A. \& Vrugtman, F. (1995): International Code of Nomenclature for Cultivated Plants. Regn. Veg. 133.

Van Raamsdonk, L.W.D. (1993): Wild and cultivated plants: the parallelism between evolution and domestication. Evol. Trends Plants 7: 73 84.

Van Raamsdonk, L.W.D. \& De Vries, T. (1996): Cultivar classification in Tulipa L. (Liliaceae). Acta Bot. Neerl. 45: 183-198.

Whalen, M.D. (1991): Taxonomy of Saccharum (Poaceae). Baileya 23: 109-125.

Wijnands, O. (1986): Linnaeus's attitude towards cultivated plants. Acta Hort. 182: 67-78.

Yeo, P.F. (1986): (89)-(90) Problems with the nomenclature of nothotaxa in the Sydney Code: a reconsideration with two proposals to amend and the withdrawal of two previous proposals. Taxon 35: $185-188$.

Zohary, D. (1984): Modes of evolution in plants under domestication. In: Grant, W.F. (ed.), Plant Biosystematics, pp.579-586, Academic Press, Toronto. 